\title{
El sesgo patriarcal del conocimiento
}

\section{The patriarchal bias in knowledge}

\author{
Mariana Favela-Calvillo
}

Fecha de recepción: 10 de enero de 2019

Fecha de aceptación: 8 de agosto de 2019

\begin{abstract}
Resumen - Ninguna periodización es neutral y las perspectivas dominantes en torno a cómo se interpreta la historia, menos. Nuestras formas de conocimiento implican un sesgo patriarcal que consiste en una manera de reduccionismo en cuando menos dos sentidos: primero, la tendencia a reducir la totalidad de la historia humana a lo que aquí denomino horizonte patriarcal, que no es sino el último suspiro de una historia mucho más larga y compleja; y segundo, incluso dentro del horizonte patriarcal esta suerte de miopía tiende a invisibilizar el papel de las mujeres y de sus aportaciones en cualquier campo. El sesgo paulatinamente se transforma en canon, se naturaliza y pasa desapercibido. Este artículo da pistas rumbo a la despatriarcalización del conocimiento y el estudio de la historia larga, entendidas como estrategias indispensables para la lucha política de las mujeres y la eliminación de los sistemas de opresión sexogenéricos.
\end{abstract}

Palabras clave:

Sesgo, patriarcal, conocimiento, despatriarcalización, epistemología feminista.
Abstract - No periodization is ever neutral, much less the dominant perspectives on how history is interpreted. Our forms of knowledge imply a patriarchal bias that constitutes a form of reductionism in at least two senses: first, the tendency to reduce the totality of human history to what I call the patriarchal horizon, and which is but the last breath of a much longer and complex story; and second, even within the patriarchal horizon, this kind of blindness tends to fade out the role of women and their contributions in any field. The bias gradually becomes a canon, it seems natural and goes unnoticed. This paper discusses the depatriarchalization of knowledge and the study of long history, both understood as indispensable strategies for the political struggle of women and the elimination of gender-generic systems of oppression.

\section{Keywords:}

patriarchal bias, knowledge, depatriarchalization, feminist epistemology. 


\section{Introducción} exclusión de las mujeres de los espacios formales donde se genera el conocimiento, particularmente en las ciencias y en las humanidades? ¿Cómo operan y se rearticulan esos procesos de exclusión? Este artículo propone una aproximación a estos cuestionamientos, desde la perspectiva de la filosofía política del conocimiento y parte de la intuición de que mientras se mantengan los sesgos patriarcales, la presencia de las mujeres en las estructuras institucionales del poder constituye una solución meramente estética que no resuelve el problema de la violencia patriarcal, y específicamente de la violencia epistémica, donde lo epistémico no debe entenderse en un sentido despolitizado, sino como una dimensión constitutiva de las múltiples formas que adoptan los mecanismos de opresión y explotación de las mujeres. En ese sentido, este texto es una crítica del esencialismo biológico todavía tan en boga, sobre todo entre los feminismos liberales, que insisten en que la presencia de las mujeres por sí misma modificaría las estructuras, sin considerar que las relaciones y los entramados de poder tienden a domesticar tanto a hombres como a mujeres. Para ponerlo en una palabra, esta reflexión se distancia de las posiciones que aplauden el "empoderamiento" de las mujeres, sin preguntarse: ¿a qué poder nos referimos? $y$, ¿a quién sirve ese poder?

En este artículo expongo dos procesos imbricados y simultáneos a través de los cuales opera el sesgo patriarcal; parto del supuesto de que eso resulta en la expulsión sistemática de las mujeres de los espacios educativos y culturales, pero también -y sobre todoen la expulsión e invisibilización de las formas de conocimiento no hegemónicas. Uno de los propósitos del trabajo es brindar herramientas para el debate, en un contexto político efervescente y en el que diferentes corrientes feministas desafortunadamente han tendido a reincorporar explicaciones naturalistas y biologizantes, tendencia a la que en otros textos me he referido como un retorno del esencialismo. Todo proceso de agitación es contradictorio y las revueltas feministas no son la excepción. Estamos en un momento de crítica radical, profundo y extendido que podemos reconocer como la cuarta ola del feminismo; vivimos tiempos de movilizaciones políticas masivas y de cambios culturales que abren posibilidades para la despatriarcalización, pero también experimentamos tiempos de violencia desmedida, una verdadera guerra contra las mujeres, de la cual el feminicidio, la violencia y la explotación sexual son los rostros más visibles, pero no los únicos. No es casual que el poder hegemónico tienda a imponer la retórica de la violencia, y que nacidas y domesticadas por este clima de terror generalizado, casi por inercia la asumamos, naturalicemos y corramos con prisa a ubicarnos en el papel de la supuesta oposición. Mas la capacidad creativa de los feminismos radica en la habilidad para no caer en el pensamiento establecido, ese que ha insistido en instalar la lógica de las oposiciones excluyentes, de la que el esencialismo biologizante es fruto. La capacidad propositiva de los feminismos reside en nuestra posibilidad no de ganar el juego establecido, sino de cambiar, más que las reglas, el tablero predispuesto. Se trata de dinamitar la lógica dominante.

En este contexto de violencia patriarcal desmedida y con una honda preocupación frente al retorno del esencialismo en distintas corrientes feministas, propongo como opción metodológica situar la mirada más allá del horizonte patriarcal, en lo que podemos llamar historia larga de la humanidad. Allí donde el poder de las mujeres se ejerció durante milenios sin implicar estratificación o dominio, cuando se incorporaron los cambios tecnológicos que hicieron posible el mantenimiento de poblaciones cada vez más numerosas. Así, en el largo aliento del tiempo, ese breve pero aún presente instante de la historia al que me referiré como horizonte patriarcal reaparece ya no como totalidad, sino como un periodo vigente pero corto y específico, como un suspiro que podremos desmantelar en la medida en que seamos capaces de comprender su origen y formación histórica. Un primer paso para eso es 
entender cómo el conocimiento tiende a rearticular y a reinstalar al horizonte patriarcal y en qué sentido esta siempre inacabada pretensión de totalidad constituye una forma de reduccionismo histórico, político y epistémico. Parto de la premisa de que un proceso radical de despatriarcalización implica, necesariamente, la reconsideración de los supuestos que subyacen a nuestra concepción de la existencia, de la vida y del conocimiento; de otro modo, la lucha política, incluso accidentalmente, se encaminará inevitablemente a reactualizar los viejos dogmas que sostienen este sistema de dominación.

\section{El sesgo patriarcal}

El patriarcado es un sistema de dominación que implica la expulsión invariable de las mujeres de tres estructuras fundamentales del poder formal: gobierno, educación y tenencia de la tierra. Entraña, además, la apropiación del trabajo femenino e infantil, el control de la sexualidad y de la reproducción, así como la imposición del androcentrismo y de la heteronormatividad. Impone un clima de violencia sexual que tiende a controlar y a subordinar a las mujeres en un sentido amplio, incluida cualquier manifestación de la feminidad, por ejemplo, a través del control y del ejercicio de la violencia en contra de quienes siendo asumidos como sujetos masculinos por la perspectiva dominante, muestren gestos femeninos. El patriarcado supone una ontología dicotómica que organiza la existencia en dos polos opuestos y excluyentes: masculino y femenino, en el que el primero subordina y subsume al segundo, y donde el amplio espectro entre uno y otro queda invisibilizado, reducido y estrictamente controlado a través de múltiples expresiones de violencia y de disciplinamiento, a la vez simbólicas y materiales. Pero el patriarcado es, ante todo, un tipo de organización específico y situado históricamente, hegemónico y con pretensión de totalidad cuya posibilidad de recreación depende de que sea aceptado como inherente a la humanidad, o bien, a lo que las tradiciones preponderantes han denominado "civilización"; ese periodo que en el espejo de la historia larga reaparece no como un momento culminante del conocimiento y máxima organización humana, sino como lo que aquí se denomina horizonte patriarcal.

\section{El sesgo como reduccionismo}

Sostengo que el sesgo patriarcal es una forma de reduccionismo que implica dos procesos simultáneos. Primero, la constricción de toda la historia de la humanidad a un momento específico y sorprendentemente reciente, que denomino horizonte patriarcal. Éste es un periodo cuyos primeros vestigios datan de hace cerca de cinco mil años, ${ }^{2}$ cuando algunas sociedades comenzaron un paulatino proceso de estratificación que derivó en la expulsión de las mujeres de las estructuras del poder formal. Para ponerlo en perspectiva, si los años que la humanidad ha existido equivalieran a un día, el horizonte patriarcal no ocuparía ni una hora del tiempo que hemos habitado la Tierra; sin embargo, las historiografías dominantes suelen reducir la totalidad de nuestra historia común a ese breve pero vigente lapso. En palabras de Gerda Lerner (1986, p. 37), "se ha mitificado al patriarcado al hacerlo ahistórico, eterno, invisible e invariable". En la operación se omite el papel predominante que ostentaron las mujeres en las revoluciones tecnológicas más importantes de la humanidad, esas que proveyeron de las condiciones indispensables para el crecimiento de las poblaciones; por ejemplo, las revoluciones tecnológicas que durante el neolítico permitieron el surgimiento de la agricultura, la crianza de animales, la invención de la cerámica que

2 De acuerdo con Lerner (1986, p. 8), "el periodo de 'establecimiento del patriarcado' no fue un 'evento' sino un proceso que se desarrolló durante un periodo de cerca de 2,500 años, de aproximadamente 3,100 al 600 a.n.e. Ocurrió, incluso en el antiguo cercano oriente, a diferentes ritmos, en diferentes tiempos y en distintas sociedades". En otras latitudes lo que se observa tampoco es un cambio abrupto ni total, sino un conjunto de modificaciones que se suceden paulatinamente y no logran consolidarse sino miles de años después. De tal modo que de los cinco milenios que pueden reconocerse como horizonte patriarcal, cerca de la mitad corresponden con ese progresivo proceso de desplazamiento y exclusión de las mujeres. 
fue indispensable para la cocción y la conservación de los alimentos, la cestería y el tejido, que fueron las primeras formas de escritura. Como podemos corroborar gracias a numerosos vestigios arqueológicos, las investigaciones en Antropología Forense y las cada vez más precisas herramientas para datar las reliquias materiales, el rol fundamental que desempeñaron las mujeres en el mantenimiento de la vida las dotó de una condición privilegiada, sin que ello significara la estratificación de las comunidades humanas.

El reduccionismo opera no sólo al constreñir la totalidad de la historia humana a su último parpadeo; más grave aún, las investigaciones marcadas por el sesgo reproducen una suerte de miopía en la medida en que interpretan tanto al pasado largo como al reciente en función de los valores, criterios y dogmas contemporáneos, lo que se vincula con el siguiente rasgo del sesgo patriarcal. El segundo sentido en el que constituye un reduccionismo es en la medida en que propicia la invisibilización y el desconocimiento sistemático del papel de las mujeres no sólo en la historia larga, sino dentro del propio horizonte patriarcal, y particularmente en los campos de la política institucional y del conocimiento. La exclusión de las mujeres ha derivado en la naturalización de criterios androcéntricos que terminan por garantizar el predominio masculino en espacios culturales, literarios y científicos. Autoras como Londa Schibienger (1993), Sandra Harding (1996), Mary Louisse Pratt (2000) y Riane Eisler (2005), entre muchas otras, han documentado cómo a pesar del carácter inestable e históricamente variable del canon, los criterios de marginación se mantienen. Podemos identificar cuando menos tres mecanismos a través de los cuales se rearticula el sesgo patriarcal en las diferentes corrientes de pensamiento: primero, el proceso de "naturalización" del orden vigente y de las relaciones de dominación; segundo, la invisibilización del poder y de la obra de las mujeres; y, tercero, el carácter autorreferencial del canon y su consiguiente configuración como artilugio de exclusión de las formas de conocimiento de los grupos no hegemónicos.
El sesgo patriarcal es, además, una forma de discriminación epistémica que en la actualidad está atravesada por relaciones coloniales, como el racismo estructural, y que se desenvuelve en un contexto marcado por la expansión, la explotación y la dominación capitalistas. Sin embargo, dicho sesgo coexiste con múltiples maneras no hegemónicas de conocimiento que son excluidas pero que persisten y se reactualizan constantemente. Para resquebrajarlo y a la miopía que impone, propongo mirar la historia larga y en ella las diversas y cambiantes expresiones tanto de poder como de conocimiento.

\section{La historia larga}

Ninguna periodización es neutral y aunque sean arbitrarias, no por eso son casuales. Son el reflejo de los valores y de los supuestos pero no de quienes vivieron en las épocas a las que se refieren, sino de quienes las disponen. Hablar de etapas, por ejemplo, presupone ya una temporalidad lineal y sucesiva, propia de la modernidad y por lo general comprometida con nociones como el progreso. Es injustificado que un periodo tan prolongado como la Ilamada era lítica (30,00-2,500 a.n.e) quede reducido a una misma "etapa" y que su estudio, con frecuencia, sea puesto de lado. Pinturas murales, cocinas, entierros, herramientas, santuarios, cerámicas y piezas de orfebrería han dejado huella de un culto a la feminidad que se extendió por Eurasia durante este intervalo. En El cáliz y la espada, Riane Eisler reconstruye la importancia del culto a la feminidad en el arte paleolítico y afirma que "las representaciones y símbolos femeninos asumían un papel primordial" (Eisler, 2005, p. 13). Narra, además, un conjunto de ejemplos sobre cómo los prejuicios de los estudiosos los llevó a ignorar los descubrimientos que indicaban no sólo la existencia de estos cultos ginocéntricos y sus símbolos -como el poder vivificante de la sangre y la asociación entre la mujer, el proporcionamiento y el mantenimiento de la vida-, sino el papel trascendental 
que en general jugaban las mujeres dentro de estas comunidades.

Uno de los mitos más comunes sobre este periodo es el del hombre-cazador/mujer-recolectora, que Eisler identifica como un ejemplo de la proyección de estereotipos. Al respecto, Lerner afirma que

la explicación del hombre-cazador ha sido refutada por la evidencia antropológica acerca de las sociedades cazadoras-recolectoras. En la mayoría de estas sociedades, la caza mayor es una búsqueda auxiliar, mientras que el suministro principal de alimentos se proporciona a través de la recolección y de actividades de caza menor (Lerner, 1986, p. 17).

Sobre el tema, Elise Boulding (1983), en interpretación de Lerner, ha señalado que "este mito y su perpetuación son creaciones que sirven al interés de mantener la supremacía y la hegemonía masculinas" (Lerner, 1986, p. 17). Las anteriores afirmaciones han sido corroboradas por recientes descubrimientos arqueológicos, como los sitios excavados en Gesher Benot Ya'aqov (Goren-Inbar et al., 2004), y por las nuevas tecnologías de investigación ósea que permiten conocer con exactitud la composición de la dieta de las poblaciones paleolíticas.

Vale la pena recuperar las consideraciones que María J. Rodríguez-Shadow ha hecho respecto de Mesoamérica en la etapa lítica, periodo en el que "los restos óseos analizados no indican diferencias en la dieta de hombres y mujeres", por lo que "es razonable suponer que no había ideas de supremacía masculina" (Rodríguez-Shadow, 2007, p. 50). En ese entonces, la recolección de víveres y su conversión en alimentos era realizada por las mujeres y los insumos que reunían "constituyeron al menos 75\% de la dieta del grupo. La recolección y no la cinegética fue el medio principal para satisfacer la mayor parte de los requerimientos alimenticios de las comunidades nómadas tempranas." (Rodríguez-Shadow, 2007, p. 50). Fue cuando las mujeres también "transformaron diversas fibras vegetales y pieles de animales en ropas que los protegían de las inclemencias del tiempo y otras que se empleaban en la construcción de refugios y enseres para almacenar alimentos" (Rodríguez-Shadow, 2007, p. 51).

Tanto en Eurasia como en América, los cultos a la feminidad sobrevivieron en múltiples manifestaciones y trascendieron hasta el neolítico, una etapa marcada por importantes aportaciones tecnológicas, en particular por la revolución agrícola, que comenzó hace cerca de 10 mil años. Poco a poco la historia se ha extendido y procesos que de forma canónica servían para identificar a las poblaciones como supuestamente "civilizadas", han resultado ser más antiguos de lo que se pensaba. De acuerdo con los descubrimientos de la arqueóloga Marija Gimbutas (1965), en la región que hoy se conoce como los Balcanes, entre los años 7000 y 3500 a.n.e prosperaron poblaciones que sembraron cebada, trigo y diversos tipos de legumbres, criaron animales y los adaptaron a sus necesidades. Gimbutas sostiene que en esa área se pueden encontrar todos los animales "domésticos" conocidos hoy, excepto los caballos. Desarrollaron cerámicas y sofisticados trabajos en hueso y piedra, trabajaron metales como el cobre, al menos desde el 5500 a.n.e., usaron barcos y tendieron redes de comercio; pero lo que más llamó la atención de la arqueóloga fue la ausencia de fortificaciones y de armas, lo que la llevó a intuir el carácter pacífico de estos asentamientos agrícolas. Existía la división sexual del trabajo, pero no se traducía en dominación. Eran sociedades establecidas por línea materna y con un marcado culto por la feminidad. Poco después de que Gimbutas formulara su método Kurgan, en los albores de la década de los 60, los hallazgos de Çatal Hüyuk y Hacilar en la antigua Anatolia, hoy Turquía, agitarían la arqueología al revelar la existencia de sofisticadas sociedades agrícolas sin desigualdades sociales. El diálogo entre los feminismos y la arqueología en torno al papel de las mujeres en la prehistoria sacudió las consideraciones que, como sostiene Lerner (1987, p. 18), después del siglo XIX sustituyeron las estimaciones religiosas por "explicaciones" científicas para justificar y legitimar la supuesta inferioridad de la mujer. A partir 
de los descubrimientos arqueológicos fue inevitable reconocer el rol fundamental que jugaron las mujeres durante la etapa lítica, y en particular durante las revoluciones tecnológicas que se suscitaron hace 10 mil años; sobre todo, fue posible conocer sociedades agrarias sumamente complejas pero no estratificadas, entre ellas, Creta.

La historia de Creta se extiende a lo largo de casi 5 mil años. De acuerdo con Eisler, su historia comienza "alrededor de 6000 a. C., cuando una pequeña colonia de inmigrantes, probablemente de Anatolia, llegó por primera vez al litoral de la isla" (Eisler, 2005, p. 30). Llevaban con ellas, afirma la autora de El cáliz y la espada, el culto a la Diosa y las tecnologías agrarias, y durante los siguientes cuatro milenios mantendrían un "adelanto tecnológico lento pero estable". Aprendieron el manejo de los metales, la cerámica, el comercio y la agricultura. "2000 a. C, Creta entró en lo que los arqueólogos denominan el periodo minoico medio o palaciego antiguo. Este periodo ya estaba bien dentro de la Edad de Bronce", durante el cual en el resto del mundo el culto a la Diosa y al poder de las mujeres había sido paulatinamente desplazado por deidades guerreras masculinas, pero en Creta la Diosa mantuvo su presencia. La ciudad floreció y con ella su arquitectura, contaba con un complejo sistema de suministro de agua, de pavimentación y de recolección de desechos. El gobierno tendió a centralizarse y estaba organizado en una perfeccionada burocracia, pero la economía seguía siendo eminentemente agraria y no hay vestigios de guerras o de la elaboración de instrumentos bélicos. Existía un uso sofisticado de los metales para la elaboración de herramientas agrícolas, como el azadón. En torno a Creta, en poblados vecinos, se expendieron la estratificación social, las guerras y el declive de la condición de las mujeres. Rodeada de enfrentamientos, Creta se mantuvo en paz, se consolidó como una potencia comercial y marítima mientras las mujeres eran parte de la vida pública y la Diosa era aún la madre proveedora y sostén de la existencia, hasta que hace 3,200 años, en la transición de la edad del cobre a la de bronce, los pueblos bélicos, jerárquicos y de marcado culto a divinidades masculinas se impusieron desde las estepas del norte. La guerra se implantó y, de acuerdo con Eisler, también el culto por la espada. La sociedad se estratificó y el antiguo esplendor arquitectónico y artístico se detuvo y aun retrocedió. La caída de Creta significa para la autora el fin de una era, pero su existencia es prueba de que el desarrollo tecnológico no sigue una línea ascendente, sino que es interrumpido por grandes regresiones. ¿Y si aquello que las historiografías dominantes llamaron los inicios de la civilización no fueran sino los albores del horizonte patriarcal? ¿Qué compromisos políticos implican las periodizaciones tradicionales?

\section{Naturalización del orden social y el canon como mecanismo de exclusión}

Filósofas e historiadoras de la ciencia como Londa Schiebinger (1993) han remarcado que la cuestión en torno al papel de las mujeres en la ciencia no es simplemente un asunto de equidad, en términos de que deberíamos contar con las posibilidades estructurales para cursar los mismos estudios que los varones. El problema fundamental, como sostiene Schiebinger, es de conocimiento. Quiénes hacen ciencia influye -e incluso determina- el tipo de conocimiento que se genera. La supuesta neutralidad del conocimiento científico ha quedado claro, es una pretensión construida históricamente y que tiende a naturalizar perspectivas androcéntricas y heteronormadas.

La filosofía de la ciencia ha estudiado a detalle cómo nuestro conocimiento está intervenido por concepciones y deseos que suelen pasar desapercibidos, pero que juegan un papel preponderante al decidir qué se considera conocimiento, o bien qué investigaciones merecen desarrollarse y cuáles fuentes de autoridad o métodos son válidos o pertinentes. De acuerdo con Schiebinger, paulatinamente se ha abandonado la perspectiva que centraba el problema exclusivamente en las mujeres, hoy los debates reconocen que la 
pregunta sobre por qué su presencia en las instituciones educativas, científicas y culturales es tan escasa en comparación con la de los varones nos obliga a reconocer que uno de los rostros de la discriminación estructural que les afecta es el sesgo patriarcal, ese racero que delimita qué es y qué no es conocimiento válido.

Al estudiar la filosofía experimental del siglo XVII en el marco de las crisis políticas que aquejaban a Inglaterra, Steve Shapin notó que la convulsión política obligó a reconsiderar las herramientas, técnicas y conocimientos preexistentes. El método, escribe Shapin (2000, p. 160), "entendido en términos generales, es el remedio preferido para los problemas de orden intelectual." En la Revolución Científica afirma que "los debates sobre el método adquieren un significado mayor cuando se considera que el orden de la sociedad depende, en buena medida, de que se descubra el método correcto de conseguir la creencia y de que se difunda" (Shapin, 2000, p. 160). Una intuición que desarrolló en coautoría con Simon Schaffer en Leviathan y la bomba del vacío. Hobbes, Boyle y la vida experimental (Shapin y Schaffer, 2005) explica cómo durante la segunda mitad del siglo XVII la filosofía natural codificó y estandarizó los registros de la experimentación tomando como ejemplo el modelo legal. ¿Qué sucedió?, ¿cuándo?, ¿đónde?, ¿quiénes y cuántas personas lo testifican?, ¿son confiables aquellas personas? Las descripciones suelen ser exageradamente detalladas y su pretensión de neutralidad imitaba los registros policiacos y legalistas. Ese es el origen del modelo que inspiró a los informes experimentales que todavía hoy codifican las investigaciones en prácticamente todas las áreas del conocimiento.

En medio de la convulsión política y en la búsqueda de estabilidad, los experimentadores de la Royal Society "presentaron sus comunidades como limitadas, disciplinadas y seguras"(Shapin y Schaffer, 2005, p. 434). A finales de 1650, de acuerdo con Shapin y Schaffer, dedicaron buena parte de sus esfuerzos a establecer lo que los historiadores de la ciencia denominan como "las reglas de la tecnología literaria del programa experimental", y que implicaban una forma rígida y única de prosa científica. Para eso siguieron el modelo legal, que para entonces se presumía como el más confiable. Preocupadas por la legitimidad y la credibilidad de sus explicaciones, las sociedades científicas replicaron el patrón de testificación, de descripciones exhaustivas y la casi ridícula acumulación de casos particulares. Sin embargo, el modelo de registro estandarizado durante el siglo XVII no era del todo nuevo, incorporaba la observación y la experimentación al antiguo modelo del tratado filosófico, aquel que supone la posibilidad de demostración a partir de una introducción o justificación del problema, exposición de las premisas y comprobación a través de un proceso lógico o argumentativo. Con las modificaciones del siglo XVII el modelo ha persistido en buena parte de las ciencias y gracias a los naturalistas ganó terreno también en el pensamiento filosófico, hasta convertirse en el canon dominante. Se mantuvo hasta finales del siglo XIX y principios del XX, cuando en el marco de la formación de los Estados nacionales proliferaron nuevas disciplinas, cuya credibilidad y estatus científico dependió de la aceptación y de la aplicación rigurosa del modelo convencional. Todavía hoy la aspiración de las comunidades de conocimiento para ser reconocidas como disciplinas científicas se manifiesta en la reproducción -muchas veces acrítica o dogmática- del referido modelo.

Este canon, además, es autorreferencial. Nada fuera de él se considera correcto, confiable o veraz. Opera como la traza de las ciudades, excluye y margina. Separa. Cercena. Codifica los márgenes de la racionalidad, de lo demostrable y de la credibilidad, pero no es ni nunca ha sido neutral. Mary Louise Pratt (2000, p. 71) escribió que "los cánones se construyen en torno a intereses e ideologías dominantes de clase género y raza" $y$, por supuesto, las humanidades no son la excepción. En "'No me interrumpas': las mujeres y el ensayo latinoamericano", Pratt afirma que la historia del ensayo latinoamericano, salvo muy pocas excepciones, revela un monopolio masculino. Pratt se inspira en 
Victoria Ocampo, quien en La mujer y su expresión, charla emitida en 1935, narra que en un viaje en barco de Buenos Aires a Berlín escuchó por casualidad la conversación entre un hombre de negocios y su esposa. "Hablaba a su mujer para hacer unos encargos", escribe Ocampo, "Empezó así: 'No me interrumpas'. Ella obedeció tan bien y él tomó tan en serio su monólogo, que los tres minutos reglamentarios transcurrieron sin que la pobre mujer tuviera ocasión de emitir un sonido" (Ocampo, 2000, p. 61). La autora suspendió la anécdota para referirse a su público:

Pues bien, yo que he sido invitada a venir a hablar y que se me paga por hacerlo, quisiera deciros: 'Interrumpidme. Este monólogo no me hace feliz. Es a vosotros a quienes quiero hablar y no a mí misma. Os quiero sentir presentes. ¿Y cómo podría yo saber que estáis presentes, que me escucháis, sino me interrumpís?

Y prosigue: "Me temo que este sentimiento sea muy femenino. Si el monólogo no basta a la felicidad de las mujeres, parece haber bastado desde hace siglos a la de los hombres". Creo-sostiene la escritora argentina- "que, desde hace siglos, toda conversación entre el hombre y la mujer, apenas entran en cierto terreno, empieza por un: 'no me interrumpas' de parte del hombre. Hasta ahora el monólogo parece haber sido la manera predilecta de expresión adoptada por él (la conversación entre hombres no es sino una forma dialogada de ese monólogo)". Más adelante Ocampo agrega que "la mujer se ha resignado a repetir, por lo común, migajas del monólogo masculino disimulando a veces entre ellas algo de su cosecha" (Ocampo, 2000, p. 63). Sin embargo, la permanencia del canon no es resultado de la mera contención o autocensura femenina; como Pratt señala, la naturalización del canon ocurre de distintos modos, la exclusión puede ser resultado de razones extraliterarias, como en el caso de obras que habiendo circulado en su época son rechazadas y marginadas por el simple hecho de haber sido escritas por mujeres. Otro modo de descarte es que "los textos escritos por miembros de grupos sociales subordinados o marginales, leídos según los códigos hegemónicos, parecerán carecer de calidad que justifique su inclusión" (Pratt, 2000, p. 71). Quienes han sido formados exclusivamente por textos canónicos, sostiene Pratt (2000, p. 72), "carecerán de los conocimientos necesarios para valorar la escritura de grupos subordinados o excluidos", de modo que así logra mantenerse el carácter autorreferencial.

Los procesos antes descritos derivan en una comprensión parcial de nuestra historia, pero también en la exclusión sistemática de las mujeres de los espacios de poder $y$, sobre todo, en la imposibilidad de intervenir en las formas en que se concibe el poder en sí mismo. La marginación de las mujeres de los entornos de conocimiento no es casual, sino parte sustantiva del paulatino pero constante avasallamiento patriarcal. En la medida en que el patriarcado es un sistema que abarca cada aspecto de la vida y en el que tanto mujeres como hombres hemos sido domesticados, la presencia de mujeres en posiciones de poder, y en específico en donde se genera el conocimiento, es una condición necesaria mas no suficiente para la transformación radical. La posibilidad real de cambio vendrá de nuestra capacidad de mirar más allá del horizonte impuesto, es decir, del patriarcal.

\section{Una pregunta abierta}

El diálogo entre las investigaciones arqueológicas y la historia de las mujeres ha llevado a investigadoras como María J. Rodríguez (2007) y Blanca Solares (2007), entre otras, a plantear interesantes preguntas respecto de la condición de las mujeres en Mesoamérica, antes del desembarco colonial. Dichas indagaciones, a grandes rasgos, indican que la expulsión de las mujeres de los espacios de poder formal, como el político, la limitación

${ }^{3}$ Shadow ubica el desplazamiento de la antigua equidad entre los géneros alrededor del Preclásico temprano (1200-400 a. C). 
al acceso a la tierra, así como la apropiación de su trabajo fueron procesos que se registraron de manera relativamente tardía ${ }^{3}$ y nunca total. A eso es necesario sumar que no caben generalizaciones sobre un área cultural tan extensa y que abarca a pueblos tan diferentes. La discusión amerita una perspectiva que atienda las especificidades de cada época y de cada comunidad, tarea que se complica si consideramos las investigaciones de Gudrun Lenkersdorf, quien a través de un exhaustivo trabajo de archivo documenta la diversidad de principios organizativos en diferentes pueblos mayenses, quienes en la víspera del desembarco español ejercían formas de gobierno en común o de gobierno compartido. El caso es relevante, pues muestra que pueblos que durante lo que se conoce como la época maya clásica establecieron sistemas altamente jerarquizados y militarizados, previo al desembarco colonial habían transitado a formas de gobierno participativas y descentralizadas, lo que incluso ha llevado a algunos autores como Robert Sharer a plantear que la época clásica maya sería una desviación transitoria (Lenkersdorf, 2010, p. 133).

La información disponible nos obliga a varias reflexiones: primero, a renunciar a la tendencia que insiste en homologar una zona tan extensa y diversa, tanto en términos culturales, como territoriales y temporales, de modo que así como en el periodo colonial, en el anterior a la llegada de las tropas españolas no es posible ni deseable establecer generalizaciones que corren el riesgo de fortalecer interpretaciones ahistóricas y esencialistas; segundo, el estudio específico de los casos apunta a que la interpretación de acuerdo con la cual los pueblos mesoamericanos transitaron del nomadismo al sedentarismo y posteriormente de comunidades poco densas y dispersas a unidades centralizadas y de mayor "desarrollo", es en sí misma una concepción colonial que no nos permite comprender la historia. No hay relación entre nomadismo o sedentarismo y mayor o menor desarrollo cultural, pues la idea del progreso cultural y de la complejidad de las sociedades no sólo está impregnada sino que es la manifestación de un conjunto de prejuicios coloniales. Del mismo modo, el hecho de que la historiografía colonial haya atribuido a las poblaciones altamente jerarquizadas, militarizadas y con economías tributarias, el carácter de superioridad es un prejuicio que debe ser desmantelado.

Si insistimos en encontrar tendencias en la historia larga de Mesoamérica lo que sí podemos sostener, gracias a los registros, es que existe una relación directa entre el auge de los gobiernos militarizados con economías tributarias que dependían de la explotación del trabajo agrario y fundamentalmente del femenino con la paulatina expulsión de las mujeres de los espacios de poder, que revelan algunas fuentes coloniales. Este proceso particular se corresponde con la expansión de los Estados militaristas y los sistemas de economía tributaria. Restringir la historia larga mesoamericana a ese momento específico y después conceder que en ese periodo particular no existían otras formas organizativas, es también una manera de reduccionismo. Por otro lado, negar del todo la existencia de la explotación de las mujeres no rompe la lógica imperante, simplemente la invierte, y como se dijo al inicio de este artículo, en la medida en que no cuestiona los supuestos subyacentes, ese tipo de inversiones simétricas no debilitan sino que tienden a fortalecer al pensamiento dominante.

Sin embargo, la pregunta que permanece abierta atiende a la pertinencia de extrapolar conceptos como el de patriarcado para explicar procesos en contextos ajenos al euroasiático, como la condición de las mujeres en Mesoamérica antes del arribo español. Mi intuición es que se pueden establecer diálogos que nos permitan comprender procesos semejantes y específicamente aquel que en mi consideración es el elemento central que en diferentes contextos ha posibilitado la expansión de sistemas de opresión contra las mujeres, me refiero a la apropiación del trabajo agrario y simultáneamente del trabajo de ellas como condición para el ensanchamiento de 
regímenes militaristas y altamente centralizados. Las diferentes sociedades en las que se ejerce el dominio sistemático sobre las mujeres suelen estar militarizadas, jerarquizadas y centralizadas, cuyas economías dependen de la apropiación tanto del trabajo agrario como de la explotación del trabajo femenino. En contraste, las sociedades que no comparten esas características por lo general presentan condiciones diversas, que pueden o no tender a la dominación de las mujeres. Dicho de otro modo, en los casos en los que no hay apropiación del trabajo agrario, la condición de las mujeres puede ser de diferentes tipos, no obstante, no he encontrado ejemplos en los que exista apropiación del trabajo agrario, militarización, centralización sin que haya apropiación del trabajo femenino y violencia desmedida contra las mujeres.

El ejercicio de comprensión histórica que se propone implica romper con el sesgo patriarcal y renunciar a periodizaciones y a prejuicios reduccionistas. Demanda aceptar que no hay procesos únicos, homogéneos ni unívocos, que en los mismos periodos históricos podemos encontrar diferentes formas organizativas y que no todas deben ni pueden ser subsumidas en las mismas categorías, pues un proceso radical de despatriarcalización supone sobre todo una implosión de los conceptos, pero sobre todo de la tendencia taxonomizante del racionalismo. En conclusión, una estrategia para escapar a la miopía y reconocer otras formas organizativas tanto en la historia larga como en la presente es situar el carácter particular y reciente del horizonte patriarcal.

\section{Referencias}

Eisler, R. (2005). El cáliz y la espada. La mujer como fuerza en la historia. México: Editorial Pax-Cuatro Vientos.

Gimbutas, M. (1965). Bronze Age cultures in central and eastern Europe. Netherlands: Mouton \& Co.
Goren-Inbar, N. Alperson, N., Kislev, M. E., Simchoni, O., Melamed, Y., Ben-Nun, A. \& Werker, E. (2004). Evidence of Hominin Control of Fire at Gesher Benot Ya`aqov, Israel. Science, 304(5671), 725-727.

Harding, S. (1996). Ciencia y feminismo. Trad. Pablo Manzano. España: Ediciones Morata.

Lenkersdorf, G. (2010). Repúblicas de indios: Pueblos mayas en Chiapas, siglo XVI. México: Plaza y Valdés.

Lerner, G. (1986). The creation of patriarchy. New York: Oxford University Press.

Ocampo, V. (2000). La mujer y su expresión. Debate feminista, 21, 61-69.

Pratt, M. L. (2000). No me interrumpas: las mujeres y el ensayo latinoamericano. Debate feminista, 21, 70-88.

Rodríguez-Shadow, M. (2007). Las mujeres en Mesoamérica prehispánica. México: Universidad Autónoma del Estado de Morelos.

Schibienger, L. (1993). Nature's body: Gender in the making of modern science. Rutgers University Press.

Shapin, S. (2000). La revolución científica. Una interpretación alternativa. Trad. José Romo Feito. España: Paidós.

Shapin, S. \& Schaffer, S. (2005). El Leviathan y la bomba de vacío. Hobbes, Boyle y la vida experimental. Trad. Alfonso Buch. Argentina: Universidad Nacional de Quilmes.

Solares, B. (2007). Madre terrible. La diosa en la religión del México Antiguo. México: Anthropos. 


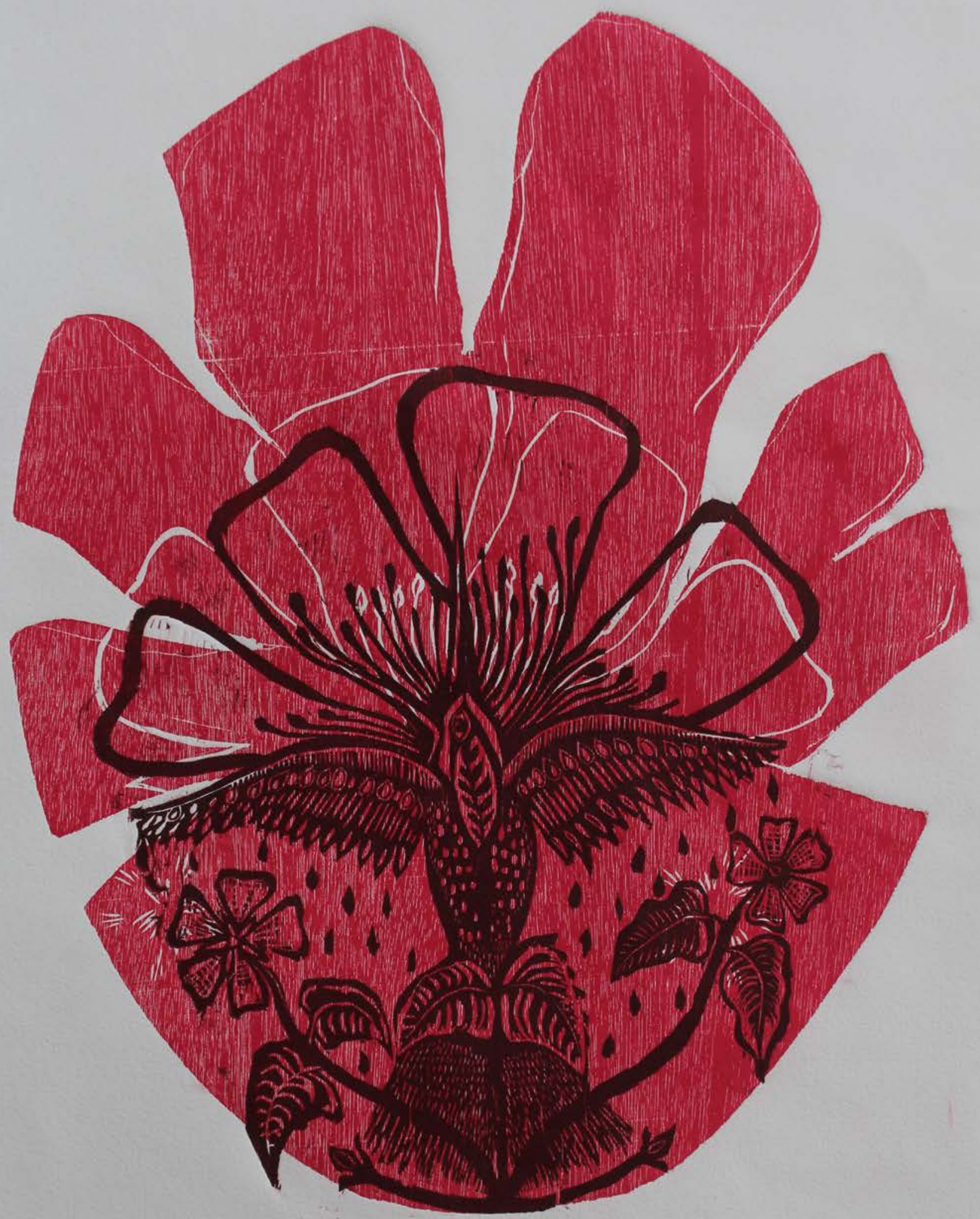

"Somos semillas de libertad" Xilografía $30 \times 60 \mathrm{~cm}$ 2019 


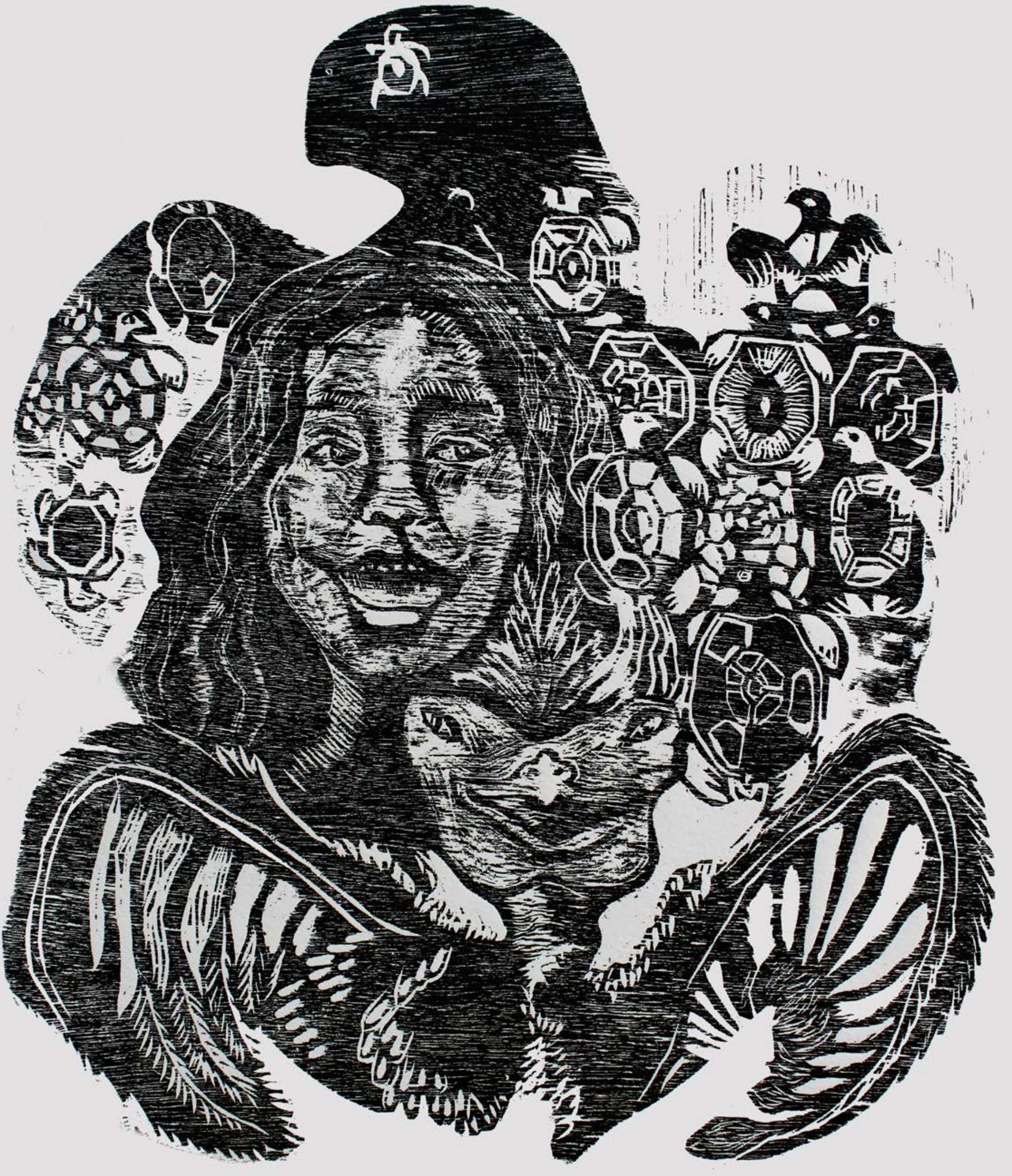

"Alegría"

Xilografía

$60 \times 65 \mathrm{~cm}$ 